\title{
Evolución de la gestión del riesgo en el sector agrario español: De la economía preindustrial a los seguros
}

\author{
Jerònia Pons-Pons y Juan Carpio Elías
}

\begin{abstract}
PALABRAS CLAVE: riesgo, seguro agrario, mutualismo, compañías de seguro.
\end{abstract}

JEL CODES: G22, G23, Q14, Q28.

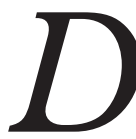
esde una visión a largo plazo (de los siglos modernos a la Guerra Civil) analizamos cómo el mundo rural se enfrenta a los riesgos imprevistos que provocaban graves pérdidas materiales. Para la Edad Moderna esta problemática se ha estudiado con fuentes notariales basadas en los contratos de arrendamiento. Para los siglos XIX Y XX acudimos a una diversidad de fuentes, como estatutos y balances de compañias, revistas comerciales, la Gaceta de Madrid y estadísticas oficiales de seguro. El análisis muestra la pervivencia de prácticas propias de la Edad Moderna hasta el siglo XX. El periodo contemporáneo se caracteriza por la dificultad de introducción del seguro agrario con una escasa participación de compañias de seguro privado y el recurso a las mutualidades locales y provinciales. El desinterés de las compañias de seguro generales por los ramos agrarios se evidencia en el insignificante peso de las primas de estos ramos en el total del negocio, con la modesta excepción del seguro de ganado. El mutualismo, en especial en el norte de España, busca apoyo en las instituciones públicas como las diputaciones. Finalmente, en las primeras décadas del siglo $\mathrm{XX}$, la gran patronal agraria presionó para que fuera el Estado quien progresivamente asumiera un sistema de cobertura agrario. 


\section{Evolution of risk management in the spanish agricultural sector: From a pre-industrial economy to insurance}

\section{KEYWORDS: risk, agricultural insurance, mutualism, insurance companies.}

\section{JEL CODES: G22, G23, Q14, Q28.}

rom a long-term perspective (Early Modern Age until the Spanish CivilWar),
we analyse how the rural world confronted contingent risks that could cause
serious material losses. For the fifteenth to eighteenth centuries, our research relied on notarial sources based on leases. For the nineteenth and twentieth centuries, we used a variety of sources, such as company statutes and balance sheets, trade journals, the Gaceta de Madrid and official insurance statistics. The analysis shows how typical Modern Age practices continued into the twentieth century. The Late Modern period was characterised by difficulty in introducing agricultural insurance, a low level of participation by private insurance companies and recourse to local and provincial mutual societies. The disinterest of the general insurance companies in covering agricultural risk was reflected in the insignificant weight of the corresponding premiums in the overall company figures, with the modest exception of livestock insurance. Mutualism, especially in northern Spain, sought support from public institutions such as provincial councils. Finally, in the first decades of the twentieth century, major agricultural employers exerted pressure on the State to progressively assume responsibility for agricultural coverage.

Recibido: 2019-04-10 - Revisado: 2019-09-22 - Aceptado: 2019-11-14

Jerònia Pons-Pons [orcid.org/0000-0003-0491-7038] es catedrática de Historia e Instituciones Económicas en la Universidad de Sevilla. Dirección para correspondencia: Departamento de Economía e Historia Económica, Facultad de Ciencias Económicas y Empresariales, Universidad de Sevilla, Av. Ramón y Cajal, 1,41018Sevilla (España).C.e.:jpons@us.es

Juan Carpio Elías [orcid.org/0000-0001-9214-5220] es profesor asociado de Historia e Instituciones Económicas en la Universidad de Sevilla. Dirección para correspondencia: Departamento de Economía e Historia Económica, Facultad de Ciencias Económicas y Empresariales, Universidad de Sevilla, Av. Ramón y Cajal, 1, 41018 Sevilla (España).C.e.:jcarpio4@us.es 


\section{INTRODUCCIÓN}

La economía agraria se desarrolla de forma consustancial con el medio natural, de ahí que los factores de riesgo hayan tenido a lo largo de la historia una importancia fundamental a la hora de proporcionar alimentos a la sociedad ${ }^{1}$. No podemos entrar aquí en el análisis de cada uno de los riesgos, aun reconociendo que su naturaleza condiciona la posible respuesta. Todos tienen en común su persistencia hasta el siglo Xx. Existen distintas clasificaciones ante la variedad de los riesgos, pero llegan a resultados parecidos. En el mundo rural destacan, además de los incendios, los riesgos de carácter meteorológico y los de origen biológico. Otros de más difícil catalogación, pero no menor incidencia, serían los robos, a los que habría que añadir la incursión de animales en las parcelas culti$\operatorname{vadas}^{2} \mathrm{o}$, en concreto, el tránsito del ganado.

En el Antiguo Régimen los daños debidos a los imprevistos van más allá de la pérdida de rentabilidad, y pueden provocar la ruina a corto o medio plazo de la explotación agraria para el propietario o cultivador y abrir la puerta a las temidas crisis de subsistencias. Por ello, tanto desde el ámbito público como el privado, siempre se buscaron mecanismos para gestionar el riesgo con la mayor eficacia posible.

La aparición del mercado formal de seguros a finales del siglo XVIII en países como Inglaterra y Francia añadió un nuevo mecanismo de gestión del riesgo para los agricultores y ganaderos. Las escasas investigaciones sobre el tema indican que los agricultores ingleses entre 1750 y 1850 tuvieron poco acceso a los mercados formales de seguros contra los riesgos agrícolas (Stead, 2004: 339) ${ }^{3}$. Pearson $(1997,2002)$, en su investigación sobre el seguro durante la revolución industrial inglesa, aporta diversas razones por las

1. La variedad de riesgos ha sido muy extensa. En todo momento, han pesado mucho los derivados de las alteraciones meteorológicas. Otros han ido despareciendo con el tiempo, como es el caso de los lobos o la temida langosta. Por la importancia económica y la abundancia de fuentes, plagas como la langosta y la filoxera han sido las que han ocupado mayor atención, aunque han existido una gran diversidad de plagas sobre el campo español (AzCÁRATE, 1996). A las condiciones climáticas y biológicas HUNEK (1986) añade el medio socioeconómico agrario, la posición social y la transformación de las sociedades locales y la alteración de sus identidades.

2. MCCloskey (1991) llama la atención sobre los efectos de vecindad con las consecuencias que provoca cuando se escapa el ganado e invade la parcela del vecino.

3. En el caso de Gran Bretaña, a pesar del importante desarrollo de la actividad aseguradora, las investigaciones sobre el seguro agrario son escasas. Cabe acudir a un clásico como DINSDALE (1954), que recoge en su obra sobre el seguro de accidentes dos breves capítulos relacionados con el seguro agrario, uno destinado al seguro de pedrisco y otro al ramo de ganado. Una aportación más reciente sobre este último ramo procede de MATTEWS (2005) quien establece una explicación sobre la persistencia de asociaciones ganaderas y clubs de seguro de ganado locales como la fórmula más frecuente de asegurar. 
que muchas líneas de seguro, incluido el agrario, se desarrollaron lentamente en ese país: la escasa legislación gubernamental, las dificultades para medir el riesgo en ciertos ramos y la cultura corporativa conservadora de los consejos de administración de las primeras compañías de seguros limitaron la expansión de nuevos productos. Además, la literatura reunida en un estudio histórico de más de veintisiete países a nivel mundial demuestra las dificultades del desarrollo en los ramos agrarios (pedrisco, ganado, incendio de cosechas, etc.) y la concentración del negocio del seguro en ramos en los que las técnicas actuariales pudieran mejorar la selección de riesgos y el cálculo de primas (Borscheid \& Haueter, 2012). La falta de estadísticas, además de las diferencias espaciales, climáticas y de cultivos regionales fueron obstáculos para el desarrollo de un seguro científico agrario que mitigara problemas como la asimetría de la información, la selección adversa y que, en definitiva, redujera los costes de transacción.

Si esto ocurrió en Inglaterra, el país que tempranamente modernizó su agricultura y a la vez el primero que desarrolló un mercado de seguros modernos, debemos plantearnos qué ocurrió con la oferta y demanda del seguro agrario en España. En general, se acepta que los mercados de crédito o de seguro eran inexistentes o, como mucho, incompletos hasta bien avanzado el siglo xx (Carmona, 1997: 120). Uno de los aspectos más sorprendentes del análisis del mercado de seguros español por ramos en su etapa estadística (iniciada en 1908) radica en el escaso desarrollo de los seguros agrarios. Así, en 1912, en una España eminentemente rural, las primas de seguro agrario sobre la producción (ganado, pedrisco e incendio de cosechas) resultaron muy poco significativas en el negocio global. El seguro de ganado representaba únicamente un 2,7\% de todas las primas cobradas. Estos porcentajes, en lugar de incrementarse, a diferencia de otros ramos del seguro español, fueron disminuyendo hasta alcanzar en 1940 sólo el 0,23\%. El peso del seguro de incendio de cosechas y de pedrisco es difícil de evaluar, porque no aparecen como ramos específicos. Cuando el seguro de pedrisco se cuantifica como ramo independiente a partir de 1931, sus primas representan solamente un 0,4\%. E. Frax y M. J. Matilla (1998) señalaron algunas posibles razones para esta realidad: la inexistencia de mediana propiedad y la falta de estadísticas fiables que mesuraran el riesgo agrícola.

Los escasos estudios específicos sobre el seguro agrario han centrado el tema en la intervención gubernamental a partir de septiembre de 1919 con la aprobación del real decreto de 9 de septiembre de la Mutualidad Nacional del Seguro Agropecuario (Burgaz \& Pérez-Morales, 1992; Melgarejo \& López Ortiz, 2016). No clarifican las razones del escaso desarrollo del mercado privado, ni tampoco lo hicieron los estudios de los contemporáneos conocedores de la agricultura española que abordaron el tema en su momento. Sin embargo, existen abundantes indicios que nos permiten intuir que durante el siglo XIX y el primer tercio del siglo $\mathrm{xx}$ hubo numerosos proyectos e iniciativas impul- 
sadas por grupos privados, instituciones públicas de ámbito local y regional (ayuntamientos, diputaciones) y asociaciones patronales y agrarias (sindicatos y cooperativas) que, junto con el seguro comercial, trataron de paliar el riesgo agrario a través de sociedades de socorros mutuos y mutualidades. Ambos, el seguro comercial y mutual, en diferentes contextos y circunstancias, intentaron cubrir la creciente demanda del seguro en el mundo agrario. Sin embargo, los grupos de presión vinculados a la patronal agraria pretendieron y consiguieron que al final, por motivos políticos más que de distribución de rentas, gran parte del coste y el riesgo terminara en manos del Estado.

Ante este panorama el objetivo principal de este trabajo, como se pone de manifiesto desde el título, es analizar la evolución en el largo plazo de lo que acabó constituyendo el seguro agrario. Así pues, no interesan tanto los pormenores de los riesgos como la variedad de estrategias con los que se intentan afrontar, teniendo en cuenta las distintas circunstancias de las distintas etapas históricas. Nuestra prioridad es intentar establecer los principales hitos para disponer de una visión general, por lo que predomina el enfoque descriptivo, para en posteriores trabajos abordar problemáticas más particulares y aspectos más concretos.

El seguimiento de la evolución en el largo plazo ha determinado la diversidad de fuentes empleadas en este trabajo. La documentación principal para la Edad Moderna se ha centrado en los protocolos notariales y, en concreto, en los contratos de arrendamiento. Para etapas posteriores, se ha recurrido a revistas especializadas, fuentes legislativas, memorias y balances de compañías de seguro y mutuas, y prensa de la época. La aparición de estadísticas en el siglo xx ha permitido un mayor número de datos cuantitativos. A partir de estas bases documentales, se ha organizado este estudio en cuatro partes. La primera, sobre la gestión del riesgo agrario en la Edad Moderna desde el ámbito privado. El tratamiento del periodo contemporáneo se ha clasificado en tres etapas cronológicas (1830$1868 ; 1869-1907 ; 1908-1940$ ) en función de las características del mercado de seguro en el que se incluyen los ramos agrarios, pero también observando la implicación del Estado.

\section{LA GESTIÓN DEL RIESGO EN LA EDAD MODERNA}

La sociedad del Antiguo Régimen seguía manteniendo una concepción esencialmente religiosa del mundo, que abarcaba cualquier aspecto de la vida cotidiana y, en especial, los fenómenos que escapaban de la comprensión científica, como es el caso de los riesgos naturales. Lo sobrenatural se extendía sobre el acontecer de todos los hombres, cualquiera que fuese su actividad. Así pues, el recurso a la divinidad resultaba imprescindible (Pé- 
rez Samper, 2009: 138). Esto lo conocemos bastante bien gracias a la exhaustiva atención que le ha venido dedicando la historiografía en las últimas décadas ${ }^{4}$.

El conjunto de leyes, normas y prácticas establecidas para prevenir o rebajar las consecuencias de los riesgos resultaban ineficaces o insuficientes. Esas limitaciones de los remedios materiales invitaban a buscar soluciones en el ámbito espiritual o de la religiosidad popular. La respuesta sociorreligiosa colocaba a la Iglesia con una gran responsabilidad en la gestión de los riesgos. Su intervención comprendía un conjunto de actuaciones basadas en las rogativas o el amparo de los santos, pero también en la adaptación cristiana de prácticas paganas. La Iglesia contaba en sus filas con especialistas en conjuros y exorcismos, que gozaban de gran confianza y reputación en las comunidades campesinas. Con estas actuaciones la Iglesia refuerza su control social, pues la fe en su intervención era compartida por todos los sectores de la sociedad, por lo que el recurso a sus remedios se estimaba como imprescindible en el Antiguo Régimen a la hora de gestionar cualquier riesgo más o menos grave para la economía agraria.

La propia condición de imprevisto determina la imposibilidad o dificultad de una normativa. Eso no impide la intervención institucional, si no para evitar los riesgos, al menos para minorar las consecuencias de los daños padecidos, dadas las repercusiones de desorden social que pueden acompañar a una crisis de subsistencia para una economía tan dependiente de los factores de riesgo, casi siempre en precario equilibrio respecto de los recursos disponibles. Esta responsabilidad institucional comprende una actuación desde la esfera de la Administración central y otra que se desarrolla en la Administración local, aunque evidentemente guardan una estrecha relación y, en gran medida, la segunda lo que hace es concretar normativamente o llevar a cabo la ordenación prevista por la primera (Carpio, 2016). Por otra parte, también se ha interpretado la incertidumbre como un factor de cambios en la agricultura ${ }^{5}$. Otra estrategia indirecta y más limitada a la hora de disminuir el riesgo estaría relacionada con la diversificación de la producción. Este ámbito, por tanto, forma parte de la iniciativa individual del labrador, pero, dado el tipo de economía agraria, el cultivador de secano cuenta con unas posibilidades muy limitadas de diversificación, por debajo de las opciones derivadas de una agricultura de regadío

4. López Cordero y Aponte (1993: 82); Peris (2009: 341); VÁzquez Lesmes y Santiago (1993: 129); BARRIENDOS (2000: 28); Alberola (2009: 30); Christian (1991: 49). Una visión más global puede ser la obra de SANZ LARROCA (2012).

5. Para HuneK (1986), los cambios y las incertidumbres son categorías íntimamente ligadas con la actividad agrícola a los que hay que considerar conjuntamente en un nexo causa-efecto mutuo. 
(Carmona, 1997: 138). Para otras latitudes, como Inglaterra, McCloskey considera que la evitación de los riesgos es la clave para comprender el comportamiento campesino ${ }^{6}$.

La acción y respuesta frente a las inclemencias meteorológicas hay que buscarlas en la esfera de la gestión privada, dentro del ámbito de los contratos agrarios. Entre las distintas fórmulas indirectas de explotación de la tierra, ya en el siglo XvI destacan de manera claramente mayoritaria los contratos de arrendamiento. Aunque permanecen en casi todo el territorio español las formas enfitéuticas o intermedias entre propiedad y explotación, como las medianerías ${ }^{7}$, lo frecuente son los contratos a renta revisable (Yun, 1987: 171). La gestión del riesgo que podemos estudiar en este tipo de contrato agrario viene marcada por el uso o rechazo que se haga de la denominada cláusula de la esterilidad, ya presente en el ordenamiento jurídico medieval, el Código de las Partidas de Alfonso X. Los labradores podían acogerse a esta disposición para solicitar una reducción de la renta si el año había resultado adverso para la cosecha. El hecho de que este supuesto, bien para su aceptación o bien para su rechazo, fuese incluido de forma casi universal en todos los contratos refleja la fragilidad de la producción ante una variedad de circunstancias, entre las que, como en cualquier época histórica, destacan las naturales, fundamentalmente las sequías o su contrario, el exceso de lluvia. En el entramado de calidad del suelo, sistema de cultivo y técnicas agrícolas empleadas, los rendimientos serían muy previsibles de no ser por el imprevisto meteorológico, ante lo cual los que dependen de la explotación, tanto arrendadores como arrendatarios, sienten la necesidad de concertar las consecuencias del riesgo al que está sometido todos los años el ciclo de producción.

La postura más habitual es la del arrendador que exige percibir la renta por entero, al margen de cualquier circunstancia. La dureza de la condición no deja el más mínimo resquicio a la posibilidad de solicitar una reducción de la renta. Desconocemos si, llegado el caso, la cláusula se exigía siempre con este rigor o era un elemento más de fuerza en una hipotética negociación ante una cosecha mala o catastrófica. Igualmente, también podría sorprender la pervivencia en Castilla hasta pleno siglo xx de esta fórmula conocida como de riesgo y ventura, por la que el propietario elude cualquier tipo de riesgo. Esto se ha explicado como una forma de abaratar los costes de transacción. La posibilidad de compartir el riesgo del colono implica cierta capacidad de supervisión y ello requiere el mismo o mayor control que el que exige el cumplimiento del pago de la renta (Carmona

6. La prudencia campesina le hace asumir más o menos riesgos en función de la previsible rentabilidad. Una de las prácticas que, según el autor, evitó los riesgos con mayor eficacia fue la dispersión de las parcelas (MCCloskey, 1991).

7. Incluso en áreas de claro predominio de los arrendamientos, como en el valle del Guadalquivir, se produce una fuerte presencia del sistema de aparcería, que permite un tratamiento compartido del riesgo (CARPIO, 2011). 
\& Simpson, 2003: 132). Generalmente, los arrendamientos sujetos a esterilidad pueden ser considerados de carácter tradicional y en todas las zonas que hemos podido consultar, aún sin llegar a su desaparición, fueron perdiendo importancia, siendo incluido este derecho en un cada vez menor número de contratos.

Una situación similar se vivía respecto de la ganadería, en concreto, con el arrendamiento de una importante fuerza de trabajo, $\operatorname{los}_{\text {bueyes }}{ }^{8}$. Su cesión se realiza también mediante la fórmula a todo riesgo, percibiendo siempre el propietario la renta estipulada. La única relativa salvedad consiste en la inutilización de un buey por dolencia o muerte natural. En tal caso, el arrendatario se obliga a notificarlo en su oportuno momento al propietario, para que este se haga cargo del animal y obtenga un aprovechamiento derivado de la venta, tanto de la carne como de la piel. De no ser así, se establece siempre la misma condena basada en el pago íntegro de la cantidad en la que ha sido apreciado el buey, la cual es consignada en un documento notarial ${ }^{9}$. El mismo procedimiento se aplica en los arrendamientos de yeguas.

Dentro del ámbito privado el riesgo y la calamidad dieron lugar a determinadas actividades profesionales. Por lo general, estas labores no se corresponderían con una ocupación exclusiva, sino que significarían un complemento para determinadas economías campesinas. En cualquier caso, el desempeño de estas actividades estaba ligado a la gestión municipal, que era la que demandaba servicios de particulares y, por tanto, la encargada de abonar salarios o premios ${ }^{10}$. Generalmente se trataba de un recurso complementario ejercido por población de condición modesta. Podía requerir de una determinada especialización, como es el caso de los loberos, o bien ser una tarea más general en la que llegaba a emplearse incluso mano de obra infantil, como sucedía con los peones que participaban en la lucha contra la langosta. Otro espectro social ocuparían las personas dedicadas a combatir las plagas mediante conjuros valiéndose de supuestos conocimientos o poderes.

Este modelo de actuación a la hora de afrontar los riesgos en el mundo agrario, propio del Antiguo Régimen, perdura hasta bien entrado el siglo XIx, al mismo tiempo que persiste la búsqueda de soluciones sociorreligiosas, tanto en España como en otros paí-

8. En otras áreas de la Península con el ganado de labor se recurre más al sistema de aparcería (MARCOS, 2000: 219).

9. Los bueyes, al igual que las yeguas de trilla, eran apreciados en un valor del que debían responder los arrendatarios en caso de algún percance. De la misma forma se redactaban cláusulas específicas sobre el buen tratamiento que deben recibir los animales (CARPIO, 2012).

10. En Galicia, a finales del siglo XVI, se hacían públicos contratos con monteros cualificados en la caza del lobo. Los cazadores se comprometían a recorrer las feligresías concertadas varias veces a la semana y recibían una recompensa por cada ejemplar abatido (SoBRADo, 2003: 114). 
ses del entorno ${ }^{11}$. Las prácticas insertadas en los contratos particulares coexisten en muchas zonas con fórmulas que representan la génesis del seguro agrario.

\section{LOS INICIOS DEL SEGURO AGRARIO Y LAS APORTACIONES DEL MUTUALISMO, 1830-1868}

El desarrollo de un mercado de seguros en España a partir de 1830 en teoría habría podido ofrecer a los agricultores españoles un nuevo mecanismo para gestionar el riesgo agrario. Sin embargo, el seguro mercantil durante esta centuria padeció un lento crecimiento derivado de factores que afectaron a la oferta y la demanda, y que determinaron su desarrollo (Matilla, 2010; Guillem, 2010; Tortella et al., 2014). La falta de capitales, el complejo marco jurídico vinculado a los cambios políticos, institucionales y económicos obstaculizaron la creación de compañías mercantiles. A la vez, cuando se pusieron en marcha proyectos de empresas, estos se centraron en las actividades más dinámicas y lucrativas, como el seguro marítimo, de quintas o las rentas vitalicias, y en el último tercio de siglo en el seguro de vida y accidentes (Pons, 2016), olvidando el seguro agrario, mucho más complejo a la hora de medir el riesgo y establecer las primas. El mundo agrario español conoce a lo largo de todo el siglo XIX un desarrollo del asociacionismo, que pudo contribuir a la modernización del campo o la defensa de unos intereses económicos (Martín-Albo, 2016), pero que no repercutió en la evolución del seguro agrario. Existieron, no obstante, muchos proyectos a lo largo del siglo que al igual que en otros ramos buscaron en la tipología mutualista la fórmula en la que se refugiaron algunos ramos olvidados, como el propio seguro agrario. Esta tipología marcó la cobertura del riesgo agrario ante el desinterés del capital en crear compañías de seguro especializadas en los tres riesgos cubiertos en esta etapa: incendio de cosechas, pedrisco y ganado.

La misma cronología que marca la evolución del negocio del seguro determina el establecimiento de la oferta del seguro agrario. Una primera etapa, en la que hubo una gran libertad en la creación de sociedades anónimas, estuvo marcada por el Código de Comercio de 1829 y finalizaba con la restrictiva ley de 17 de enero de 1848. A las nuevas empresas se les exigía únicamente su constitución notarial y su inscripción en el Registro Mercantil, lo que facilitó la aparición de numerosas sociedades de capital, aunque de escasa supervivencia. Según Guillem (2010), la principal característica de las sociedades de seguros entre 1830 y 1848 se centraba en su escasa especialización, con objetos so-

11. Según PILuso (2012: 171), en Italia, en 1900, el editor jefe de The Review informó que los agricultores del país preferirían apelar a los santos o al gobierno que asegurar sus cosechas contra daños por granizo. 
ciales que mezclaban actividades de crédito con operaciones de seguros. Por lo que respecta al ámbito agrario, en esta etapa funcionaron sociedades constituidas como socorros agrícolas, cajas o bancos agrícolas que aseguraron contra fenómenos atmosféricos ${ }^{12}$. Algunas entidades. como La Seguridad y El Fénix, ambas bancos agrícolas que se dedicaban a préstamos hipotecarios, incluían en sus estatutos el objeto de asegurar ganado. El Fénix se congratulaba de ser la primera sociedad en España que se dedicaba al seguro de ganado. Sin embargo, estas sociedades entremezclaban los seguros agrícolas con el adelanto de dinero o semillas a agricultores y ganaderos y, en realidad, en todas ellas primó el préstamo frente al seguro. Con el tiempo estas aseguradoras fueron especializándose, algunas concentrándose en el crédito (La Esperanza, La Probidad y El Fénix), otras dedicándose al seguro (La Alianza, El Áncora o La Española).

Si las entidades que ofrecieron seguro agrario hasta 1848 habían sido escasas y limitadas, a partir de la exigente ley de ese año esta opción prácticamente desapareció y quedó reducida a unas pocas compañías centradas en el seguro marítimo ${ }^{13}$. Hasta 1869 , desde el ámbito local, regional y nacional, instituciones y propietarios agrarios impulsaron fórmulas mutuales para enfrentarse, con mayor o menor éxito, a una necesidad presente derivada del riesgo agrario. En esta etapa se producen coyunturas excepcionales en determinados ámbitos agrícolas, como en el importante cultivo de la vid que soporta la plaga del oídio a partir de 1850, con cambios que afectan a la geografía, producción y comercialización (Pan-Montojo, 1994). Sin embargo, el tratamiento de este riesgo no encuentra cobertura en las fórmulas aseguradoras del momento.

En estos momentos de difícil arranque, la iniciativa institucional resultó ser fundamental en algunos casos, aunque siempre dependiente de una respuesta inestable por parte de los principales interesados, los agricultores. El titubeante devenir, que culmina en la consolidación de una mutua con fuerte implantación, lo representa con bastante detalle el ejemplo emprendido por la Diputación Foral de Álava. Sus rasgos debieron estar presentes, en mayor o menor medida, en otras sociedades mutuales que no acabaron de fructificar. En el caso de Álava, el impulso inicial estuvo favorecido por el padecimiento en

12. La extensa literatura sobre el crédito en el mundo rural ha resaltado las diferentes modalidades existentes en la financiación de la actividad agraria: cooperativas, pósitos, cajas rurales, etc. Sin ser exhaustivos, pueden consultarse los trabajos clásicos de CARASA (2001) y MARTínez SOTO (2003). En todos ellos se puede establecer un paralelismo en las dificultades para su implantación con importantes diferencias regionales. Hallamos sociedades con experiencias mixtas (seguro y crédito) que progresivamente irán desapareciendo y separando ambos instrumentos financieros.

13. Las nuevas sociedades anónimas estaban sujetas a la inscripción en el Tribunal de Comercio, la exigencia de un capital social adecuado y a no ejercer monopolio en ningún ramo o artículo de primera necesidad (Pons, 2016: 176). 
1847 de una catástrofe por tempestades con graves pérdidas agrícolas en 12 pueblos, sin que la tesorería de la Diputación estuviese en condiciones de auxiliar a los afectados. Esta experiencia debió influir como estímulo para poner en marcha una sociedad de seguros mutuos en 1848. No obstante, a pesar de no tener problemas de financiación y satisfacer los siniestros, en dos años la débil participación la lleva a su desaparición entre 1850 y 1853 . Este fuerte carácter coyuntural ${ }^{14}$ actúa también en sentido contrario y a partir de 1854 reactivan la mutua un número elevado de localidades. El modus operandi está basado en los ayuntamientos, que son los que canalizan las relaciones y compromisos entre los socios y la mutua, de ahí que resultara tan importante la gestión de los alcaldes.

Además de las iniciativas institucionales, a partir de los años cincuenta tenemos noticias de otras sociedades promovidas desde el ámbito privado (Tabla 1). Esta experiencia de actividad mutualista a mediados del siglo XIX está muy presente en Valencia, fundamentalmente en relación con las cosechas de arroz, protegidas contra el pedrisco. En este sentido, está documentada la actividad de la Compañía La Edetana, al menos, entre 1851 y 1857. Igualmente, la captación de socios se realiza a través de los pueblos, a los que se remiten circulares insistiendo en el ahorro y en el absoluto desinterés en el ánimo de lucro, para tratar de vencer la tradicional desconfianza de los agricultores ${ }^{15}$. En esta zona levantina las entidades mutualistas tratan de hallar también implantación en el sector ganadero. Así, en junio de 1853 se aprueban los estatutos de una sociedad de seguros mutuos sobre caballerías, La Protectora ${ }^{16}$. Un año más tarde el Estado interviene sobre ellos para fijarle a la sociedad un fondo preventivo de un 3\% sobre el valor asegurado. Con ello se le autorizaba a operar no solo en Valencia, sino en otras provincias. Esta medida resultaba habitual en el control que ejercía el Gobierno sobre este tipo de entidades aseguradoras, para tratar de garantizar los recursos que permitieran cumplir con los compromisos contraídos. De la vitalidad que alcanza el mutualismo asegurador encontramos buena prueba en 1854 con La Indemnizadora, sociedad general de seguros mutuos sobre la vida de los ganados caballar, mular, asnal y vacuno. En tres meses de vida cuenta con un capital asegurado de 5,5 millones de reales ${ }^{17}$.

14. La propia sociedad en su memoria apunta las claves de este comportamiento: una escasa cosecha el año anterior, un duro y largo invierno tras ella y una pequeña subida en la cuota de reparto. Biblioteca Nacional de España (BNE), VC/3325/17. «Memoria sobre las dos Sociedades de Seguros Mutuos de Cosechas y de Edificios Rurales establecida en esta M. N. y M. L. provincia de Álava bajo la protección de la misma», 1861 .

15. Gaceta de Madrid, n. ${ }^{\circ} 6625,12 / 08 / 1852$, pp. 3-4; Gaceta de Madrid, n. ${ }^{\circ}$ 1487, 29/01/1857, p. 4.

16. Revista Los seguros, n. ${ }^{\circ} 10,15 / 12 / 1918$, pp. 354-355.

17. Gaceta de Madrid, n. ${ }^{\circ}$ 557, 11/07/1854, p. 3. 
En la misma década, en Madrid hallamos una sociedad, La Iberia Agrónoma, que revela una mayor complejidad. Además de cubrir seguros mutuos de cosechas, funcionaba como banco agrícola, ofreciendo créditos a los agricultores, y de forma complementaría constituía un montepío para pensionar a los hijos y viudas de los labradores ${ }^{18}$. En otras ocasiones, las sociedades autorizadas no llegan a constituirse nunca. Es el caso de Protección Agrícola, que vivió un período de 15 meses, entre diciembre de 1859 y marzo de 1861, en una situación anómala, operando sin haber sido constituida. En ese tiempo, se cometen irregularidades que llevan a revocar la autorización inicial y a dejar completamente sin efecto la mutua ${ }^{19}$.

El régimen mutualista característico de este período sigue unas pautas muy similares, tal y como puede deducirse de sus estatutos, un documento base para la autorización del Estado. En primer lugar, se hace constar los datos sociales de la compañía: nombre, ramo en el que opera, domicilio social, duración y órganos de administración. A continuación, se especifica con detalle el objeto del seguro, la relación de los bienes, así como los riesgos que se contemplan. La precisión lleva a citar, tanto lo que se incluye como lo que se excluye en cada caso. Generalmente, existen dos grandes coberturas, el seguro de cosechas y el de ganado, y tiene menor presencia el de edificios rurales, que es tempranamente el objeto mayoritario del seguro agrario en Inglaterra (Stead, 2004) ${ }^{20}$.

Una de las grandes dificultades con las que tropiezan las mutuas y que explicaría en parte la escasa atención de las compañías privadas sobre el sector radicaba en la dificultad de establecer tasaciones, en definitiva, la imposibilidad de disponer de datos estadísticos y suficientemente objetivos para medir los riesgos y establecer la proporcionalidad solvente al asegurar la rentabilidad de la cobertura. En este período las sociedades incluyen determinadas variables, como la clasificación de la tierra, los rendimientos obtenidos por término medio en años anteriores y el precio o valor de los productos al suscribir los seguros. Igualmente establecen un máximo y un mínimo en el valor asegurable ${ }^{21}$. Las aso-

18. En la autorización se remarcaba su carácter social: el módico interés de un $6 \%$ y 2 por comisión, acabando de una vez con la escandalosa usura que reina más que en parte alguna en los campos. Gaceta de Madrid, n. ${ }^{\circ} 1067,06 / 12 / 1855$, p. 1; Gaceta de Madrid, n. ${ }^{\circ} 1244,31 / 05 / 1856$, p. 1.

19. Su fundador y Director Velarde ha abusado del crédito de su posición, cometiendo diversas irregularidades y firmado pagarés como tal Director, que no ha recogido de la circulación, se han admitido depósitos y se ha recaudado el importe de los Seguros que ilegalmente se hacian, en lugar de limitarse sus agentes solo a promover adhesiones privadas hasta el día en que llegara a constituirse. Gaceta de Madrid, n. ${ }^{\circ}$ 95, 05/04/1861, p. 1 .

20. A veces se ofertaba un producto más completo, una asociación de bienes que se pueden asegurar independientemente. La Compañía General de Seguros Agrícolas distinguía entre cosechas, ganado lanar y cabrío, ganado caballar, mular, asnal y vacuno, y edificios rurales y su contenido.

21. BNE,VE/807/15. «Estatutos de la Aseguradora Agrícola [Texto impreso]: Compañía General de 
ciaciones locales y provinciales, con contacto directo y mejor acceso a la información, tenían mayor capacidad para reducir la incertidumbre (Mattews, 2005).

TABLA 1

Sociedades que cubren el seguro agrario

\begin{tabular}{|c|c|c|c|c|c|}
\hline Razón social & $\begin{array}{l}\text { Información } \\
\text { disponible }\end{array}$ & Sede social & Ámbito & $\begin{array}{l}\text { Tipo de } \\
\text { sociedad }\end{array}$ & Ramo \\
\hline $\begin{array}{l}\text { Seguros mutuos de cosechas } \\
\text { y edificios rurales en Álava }\end{array}$ & $1848-1861$ & Álava & Regional & Mutuas & Cosechas \\
\hline La Edetana & $1851-1856$ & Valencia & Regional & Mutua & Pedrisco \\
\hline La Indemnizadora & 1854 & Valencia & Regional & Mutua & Ganado \\
\hline La Protectora & $1853-1854$ & Valencia & Regional & Mutua & Ganado (caballerías) \\
\hline La Iberia Agrónoma & $1855-1856$ & Madrid & & Mutua & Cosechas \\
\hline La Aseguradora Agrícola & 1860 & Madrid & España-Portugal & Mutua & Cosechas \\
\hline $\begin{array}{l}\text { Compañía General } \\
\text { de Seguros Agrícolas (proyecto) }\end{array}$ & 1860 & Madrid & Nacional & Mutuas & $\begin{array}{l}\text { Cosechas, ganado, } \\
\text { incendios }\end{array}$ \\
\hline Protección Agrícola & 1861 & Madrid & & Mutua & Cosechas \\
\hline La Agricultura Española & $1862-1865$ & Madrid & Nacional & Mutua & Cosechas \\
\hline $\begin{array}{l}\text { La Ganadera. Compañía } \\
\text { Hispano-Portuguesa }\end{array}$ & 1862 & Madrid & & Mutua & Ganado \\
\hline La Previsión & 1874 & Madrid & Nacional & Mercantil & Pedrisco \\
\hline $\begin{array}{l}\text { La Previsora. Banco y Compañía } \\
\text { de Seguros Agrícolas }\end{array}$ & 1893 & Madrid & Nacional & Mercantil (SA) & Pedrisco \\
\hline La Agrícola & 1896 & Pamplona & Regional & Mercantil (SA) & Ganado \\
\hline $\begin{array}{l}\text { Agencia de La Sociedad General } \\
\text { de Seguros Agrícolas e industrial } \\
\text { (Francesa) }\end{array}$ & 1896 & Barcelona & Nacional & Mercantil & - \\
\hline La Unión Aragonesa & $1896-1897$ & Zaragoza & Regional & Mutua & Ganado \\
\hline
\end{tabular}

Fuente: Biblioteca Nacional de España. Gaceta de Madrid y Revista Ilustrada de Banca, Ferrocarriles, Industria y Seguros.

\section{LA ACTIVACIÓN DEL MERCADO DE CAPITALES Y LA OFERTA DEL SEGURO AGRARIO, 1869-1907}

Tras la Revolución de 1868 se impulsaron cambios en la regulación de las sociedades que dieron lugar a la finalización del periodo restrictivo en la creación de sociedades anónimas. El decreto de 28 de octubre de 1868 sustituyó a la ley de sociedades de 1848, que

Seguros Mutuos contra las escarchas, hielos, granizo o piedra», 1860.

Historia Agraria, 8I - Agosto 2020 - pp. 227-255 
coyunturalmente devolvió vigencia al Código de Comercio de 1829 hasta la aprobación de la ley de 19 de octubre de 1869. En este contexto, el sector asegurador se vio reactivado con nuevos proyectos, algunos de ellos en el campo del seguro agrario. No solo se crearon sociedades de seguros, sino que a su vez se abrieron las puertas al capital extranjero, lo que permitió que se instalaran en España compañías francesas, inglesas, italianas y americanas (Pons, 2008; Tortella et al., 2014: 112; Pons, 2016: 183-184) atraídas por la escasa tributación fiscal ${ }^{22}$. Alguna de ellas también operó en el seguro de cosechas o pedrisco, entidades que convivieron con proyectos mutuales diseminados por la geografía española.

Más allá de la nacionalidad, algunas sociedades apuestan por la especialización en el seguro agrario. Es el caso de la compañía española La Previsión, que se dedica al seguro contra el pedrisco y los rayos. Se conservan sus estatutos de $1874^{23}$, que pueden orientar sobre el sector en esos años. Se aseguran por una prima fija las cosechas de cereales, legumbres, viñas, olivares y árboles frutales. La prima consiste en el 0,5\% de los frutos asegurados más 8 reales por cada póliza. La única referencia para establecer los valores es la del amillaramiento oficial. El seguro se contrata por dos años y se establece como generalización el predominio del sistema de cultivo de los cereales en dos hojas que se alternan cada año. El articulado sobre los siniestros sigue el procedimiento de actuación de las décadas anteriores. Otro apartado va destinado al director general, al que se considera único representante legal de la compañía y, por tanto, todas las pólizas que puedan firmar los agentes en las provincias lo hacen como apoderados en su nombre. Estos trabajan a comisión, percibiendo el $10 \%$ de las primas. El director gestiona como único responsable toda la actividad administrativa y económica. Así, bajo una relativa apariencia de sociedad anónima, encontramos la apuesta empresarial de una persona, lo que contribuye a explicar la difícil implantación del seguro agrícola y la corta existencia de estas compañías.

Durante todo este período existe un desfase entre las posibilidades de negocio vinculadas a las necesidades de la producción agraria y el desarrollo que experimenta el seguro agrario. En la primera década del siglo xx la actividad aseguradora en este sector se puede aún calificar de incipiente, tanto en sí misma como en comparación con otros ramos que empiezan a despegar. Entre las causas que afectan a esta situación los propios contem-

22. La fiscalidad sobre las compañías no se inicia hasta 1888 cuando las compañías de seguro de vida deben pagar la contribución industrial. En 1893 se incrementó la presión fiscal estableciendo un $2 \%$ sobre las primas anuales que cobrasen las compañías y el mismo porcentaje sobre las comisiones de los agentes de seguros (Pons, 2016: 186).

23. BNE, VC/2537/54. «Reglamento para el régimen de la Compañía Española de seguros de cosechas contra pedriscos y fuego del cielo titulada La Previsión", 1874. 
poráneos destacan la falta de estadísticas ${ }^{24}$ que permitan conocer a fondo los siniestros, lo que dificulta sustancialmente la elaboración de cálculos actuariales. Otros factores estarían relacionados con la falta de capital, la mala administración o, incluso, con una excesiva expectativa de beneficio en un negocio complejo e irregular en el que las pérdidas pueden ser las protagonistas de momentos concretos. La iniciativa empresarial en algunos casos aumenta el desengaño de los agricultores, que tradicionalmente contaban con prejuicios y recelos que también dificultaban las fórmulas mutualistas.

Son frecuentes las compañías que en pocos años se ven abocadas a la quiebra en medio de una gestión irregular que impide que satisfagan sus compromisos. La ausencia de regulación en el mercado del seguro facilita la opacidad de algunas de estas sociedades que no cumplen con normas básicas, como la publicación de sus balances. A veces, las irregularidades se concentran en algún año y posteriormente la compañía se rehace operando con normalidad, como es el caso de la Unión Aragonesa en 1897 o la Protección de la Agricultura Española en $1900^{25}$. En cambio, otras muestran irregularidades desde su misma constitución, como sucede con la Cooperativa Agrícola e Industrial, que en 1898 carece de la debida personalidad, pues no tiene director, gerente ni administrador que la represente, ni tampoco domicilio social conocido. Este tipo de abusos, denunciados en la prensa especializada, alimentaba la desconfianza de los agricultores y ganaderos ${ }^{26}$. Sin embargo, otras veces se produce la desaparición de una sociedad tras unos inicios brillantes y una supuesta consolidación ${ }^{27}$.

Ante esta débil implantación del seguro agrario, algunos abogan por una solución basada en las sociedades mutuas protegidas por el Estado, es decir, el modelo dominante en Francia. La intervención del Estado liberal en el siglo XIX, como cabe suponer, resulta muy insuficiente. De forma indirecta, promueve algunas instituciones encaminadas al control de las plagas, como sería la Estación de Patología Vegetal (1888) en Madrid ${ }^{28}$ o la

24. La estadística agrícola y pecuaria había sido una tarea central de los ingenieros agrónomos, sobre todo a partir de 1879, que se constituyen como cuerpo funcionarial propio (Pan-Montojo, 2005: 149). Sus trabajos estaban ligados al Ministerio de Fomento y debido a su alcance limitado no parece que repercutieran en el negocio del seguro.

25. Revista Ilustrada de Banca, Ferrocarriles, Industria y Seguros, 25/05/1897, pp. 12-13; 10/03/1900, p. 114.

26. Revista Ilustrada de Banca, Ferrocarriles, Industria y Seguros, 10/08/1899, p. 256.

27. Es el caso de El Amparo del Agricultor. Creada en 1902 en Barcelona como compañía anónima, cuenta con delegados en todas las provincias y se permite rechazar 620 propuestas sobre seguro de ganados. Entre ellas, la de los ganaderos de Buenos Aires, que ofrecían doble prima de la que fija la tarifa por el ganado que de aquel país viene a España. Sin embargo, ya había desaparecido en 1905. Revista Ilustrada de Banca, Ferrocarriles, Industria y Seguros, 10/10/1902, p. 502.

28. Si bien la institución no resultó determinante, se reconoce una gran labor a los ingenieros que 
creación de granjas escuela experimentales, aunque habría que esperar a la segunda década del siglo xx, para que, con la creación de distintas estaciones provinciales, se intentara aplicar el control biológico de plagas (Catalá \& Guillem, 2006: 261). Tradicionalmente, en momentos puntuales marcados por catástrofes meteorológicas, las Cortes aprobaban medidas de gracia consistentes en la condonación de las contribuciones rústicas a las localidades afectadas ${ }^{29}$. Hasta 1885 los Presupuestos Generales del Estado contaban con una partida denominada Calamidades públicas y españoles desvalidos en el extranjero con la finalidad de auxiliar a la agricultura ante los grandes daños provocados por fenómenos atmosféricos. La aplicación de estos fondos, unas ciento ochenta mil pesetas, contribuía a numerosos abusos y, pese a la sólida estructura caciquil, esta partida sería suprimida. Eso no significa que los presupuestos estatales no se siguiesen viendo afectados por las catástrofes sobrevenidas ${ }^{30}$.

En 1902 el Estado decide regular el seguro agrario y elabora un proyecto de ley. El borrador sigue un criterio mixto, pues si bien deja libertad a las diputaciones para organizar el seguro, le asigna en cambio el carácter de forzoso dentro de cada una de las provincias que lo pidan y lo hace uniforme dentro de ellas. Cuando una diputación establezca el seguro mutuo, será obligatorio para todos los pueblos y propietarios de la provincia la suscripción destinada a dicho seguro. Se intenta seguir el modelo que con cierto éxito habíamos visto para Álava. Este proyecto no sería respaldado en las Cortes, con lo que perviviría la situación de vacío legal en el sector.

En esta etapa el seguro destinado a la agricultura se centra casi con exclusividad en el pedrisco y el granizo (Melgarejo \& López, 2016). A pesar de que siguen estando muy presentes riesgos como la sequía o la langosta, no se contemplan en las fórmulas aseguradoras, tanto si se trata de mutuas que se financian a través de las cuotas o de sociedades anónimas que lo hacen con las primas. En este sentido, tal como ya sucediera anteriormente con el oídio, una plaga de aún mayor trascendencia, que obliga a una intervención desigual del Estado (Pan-Montojo, 1994: 347), no despierta mecanismos de actuación en el mundo asegurador ${ }^{31}$. A la par que se especializa el objeto del seguro, se

ejercieron su dirección. Estos técnicos confeccionaron la primera memoria general sobre la langosta en España (BUJ, 1996: 167).

29. Gaceta de Madrid, 04/07/1877, p. 232.

30. En 1887 el Estado destinó un millón de pesetas a la lucha contra la plaga de langosta (BuJ, 1996: 316). Anteriormente, las cantidades habían sido claramente inferiores. Así, en el quinquenio 1856-1860, la Hacienda gastó en las catástrofes rurales 2,4 millones de pesetas; mientras entre 18611866 lo hizo por un total liquidado de 2,3 millones de pesetas, para el quinquenio 1866-1871, el gasto no sobrepasó las novecientas mil pesetas (MORAL, 1979: 75).

31. En el caso navarro la crisis filoxérica provocó una intensa reacción para remediar la plaga por 
amplía el modelo de negocio, en el sentido de que predominan ampliamente las sociedades que trabajan, tanto el seguro como el crédito ${ }^{32}$. Todo ello con un irregular reparto geográfico en cuanto a la implantación de estas sociedades, característica del siglo XIX que pervive durante el siglo $\mathrm{xx}$.

Una compañía, El Fénix Agrícola, destaca con fuerza a partir de 1906 y se convierte en líder del sector. Con ella aparecen algunas novedades, como el seguro por robo de ganado o el seguro de vida de ganados a todo riesgo. Este caso comprende no solo las muertes naturales, sino también las producidas por epidemias y contagios. Esto lleva a la compañía a una preocupación por modernizar el tratamiento de los veterinarios a la hora de prevenir y curar las enfermedades de los ganados. Es precisamente en este campo sanitario relacionado con el seguro de ganados donde se producen las principales innovaciones. En 1903, cuando comienza su andadura, otra sociedad, La Protectora Ibérica ${ }^{33}$, lo hace creando un laboratorio con todos los adelantos de la ciencia y con el objetivo de proporcionar vacunas a sus veterinarios para aplicar al ganado asegurado. En otros casos, la compañía contrata los servicios de una moderna clínica veterinaria sin que los ganaderos tengan que pagar por ello suplemento alguno ${ }^{34}$.

\section{MERCADO E INSTITUCIONES ANTE LA COBERTURA DEL RIESGO, 1908-1935}

A principios del siglo xx, el mercado asegurador podía calificarse de caótico, al no existir un organismo ni una legislación específica de control de las entidades aseguradoras y que garantizara su solvencia y las obligaciones con los asegurados. El 14 de mayo de $1908^{35}$

parte de la Asociación General de Agricultores de Navarra (LANA, 2001: 283).

32. Cabe señalar, entre otras, La Cooperativa Agrícola e Industrial, sociedad de seguros reunidos y crédito agrícola (Revista Ilustrada de Banca, Ferrocarriles, Industria y Seguros, 10/08/1899, p. 256) y, sobre todo, el Montepío Agrícola de Castilla la Nueva, con implantación en todo el territorio nacional (Revista Ilustrada de Banca, Ferrocarriles, Industria y Seguros, 25/07/1901, p. 375).

33. Se trata de una sociedad un tanto compleja, pero representativa de la falta de regulación en el sector. En ella se contemplan cinco tipos de socios, lo que le proporciona a la vez una configuración de mutua y de compañía por acciones. Revista Ilustrada de Banca, Ferrocarriles, Industria y Seguros, $10 / 12 / 1903$.

34. Es lo que hace El Amparo del Agricultor con la clínica veterinaria de Don Juan J. Ibars. Se trata de una especie de hospital hípico con quirófano y enfermería de aislamiento para posibles contagios. Revista Ilustrada de Banca, Ferrocarriles, Industria y Seguros, 10/10/1902, p. 502.

35. Por estas mismas fechas, el 21 de mayo se aprueba la Ley General de Plagas del Campo. Reúne la legislación especial sobre langosta y filoxera y las medidas de carácter general aplicables a otras plagas que pudieran presentarse. 
se aprobó la primera ley de seguros privados en España, que intentó ordenar esta actividad, en especial, discriminando aquellas entidades que ejercían el negocio sin ánimo de lucro y creando una Junta Consultiva de Seguros que vigilara el sector. A las compañías mercantiles se les exigieron depósitos y reservas mínimas para poder ser autorizadas.

A partir de la aplicación de la ley de 1908, las mutuas y sociedades de socorros mutuos debieron pedir la excepcionalidad a la ley e inscribirse en el Registro de Entidades de Seguros Exceptuadas. Este proceso se prolongó en el tiempo debido en gran parte a la escasa capacidad de inspección de la Dirección General de Seguros. En 1915, de las 1740 entidades inscritas, únicamente aparecían 57 mutualidades de seguro de ganado, 3 contra el pedrisco y 1 sobre el seguro de cosecha (Tabla 2); es decir, un total de 61 sociedades vinculadas al seguro en el sector agrario que representaban un 3,5\% del total de las mutualidades incluidas en la excepcionalidad de la ley.

\section{TABLA 2}

Entidades de seguros exceptuadas, 1911-1915

\begin{tabular}{lrrrrr}
\hline Entidades exceptuadas & \multicolumn{7}{c}{ Años $^{*}$} \\
\hline Mutualidades de seguro de ganado & 1911 & 1912 & 1913 & 1914 & 1915 \\
Mutualidades de seguro contra el pedrisco & 55 & 59 & 59 & 57 & 57 \\
Mutualidades de seguro de cosechas & - & 3 & 4 & 3 & 3 \\
\hline Total de mutuas exceptuadas & $\mathbf{1 1 5 4}$ & $\mathbf{1 2 3 1}$ & $\mathbf{1 3 1 2}$ & $\mathbf{1 3 5 2}$ & $\mathbf{1 7 4 0}$ \\
\hline
\end{tabular}

*Número de mutualidades a 31 de diciembre.

Fuente: Comisaría General de Seguros, Memoria acerca de las entidades de seguros sometidas a los preceptos de la Ley de 14 de mayo de 1908, 1917.

La complejidad en el cálculo de los riesgos, la falta de estadísticas fiables y el desinterés de los grandes propietarios agrarios, por una parte, y de las compañías de seguros generales, por otra, además de la persistencia de fórmulas tradicionales de la lucha contra el riesgo agrario, citadas en la primera parte del trabajo, no atrajeron capitales para la creación de compañías de seguro en el sector agrario. Desde la aprobación de la ley de seguros en 1908, el único ramo vinculado al negocio agrario que mantuvo cierto dinamismo fue el del ganado, tal vez por su vinculación a explotaciones más capitalistas o destinadas a la exportación ${ }^{36}$. Las compañías practicaron el seguro de cosechas, pero sus estadísticas nunca aparecieron oficialmente separadas, sino siempre incluidas en el negocio de incendios. Durante estas primeras décadas de siglo, las grandes asegurado-

36. Ese fue el caso de Argentina, donde muchas sociedades de seguros agrícolas crecieron ante la demanda generada por la exportación agraria, incluido el ganado (BLASCO \& RABETINO, 2012: 625). 
ras generales ignoraron los ramos agrarios, que dejaron en manos de compañías especializadas o mutuas.

Desde 1908 hasta 1935, en el ramo de ganado operó un pequeño grupo de compañías, pero la mayoría con escaso peso. Las cinco primeras controlaron más del $90 \%$ de las primas durante casi todo el periodo. Con el tiempo, se produjo un descenso general de su número, pero a su vez esto coincidió con una concentración en manos de una sola compañía: El Fénix Agrícola. En 1912 esta aseguradora agraria absorbía el 68,2\% del negocio del ramo, porcentaje que se mantuvo en la década de 1920, con un 62,1\% en 1920 y un $66,2 \%$ en 1925. En la década de los años treinta creció esta concentración llegando al 78,5\%. Sin embargo, y sorprendentemente, en 1933 La Mundial (Madrid) adquirió su cartera en este ramo con lo que su liderazgo se traspasó a esta compañía, que gestionó en 1935 el 82,1\% de las cuotas de mercado (Tabla 3) ${ }^{37}$.

\section{TABLA 3}

Cuota de mercado de las 5 primeras compañías que operaban en el ramo de ganado, 1912-1935 (\%)

\begin{tabular}{|c|c|c|c|c|c|c|}
\hline & 1912 & & 1915 & & 1920 & \\
\hline 1 & El Fénix Agrícola (Madrid) & 68,20 & El Fénix Agrícola (Madrid) & 68,50 & El Fénix Agrícola (Madrid) & 62,10 \\
\hline 2 & Europe Company (Madrid) & 8,55 & La Agrícola Española (Barcelona) & ) 8,34 & La Mundial Agraria (Sevilla) & 13,10 \\
\hline 3 & La Unión Catalana (Barcelona) & 7,92 & La Mundial (Madrid) & 6,74 & La Agrícola Española (Barcelona) & 9,34 \\
\hline 4 & La Agrícola (Pamplona) & 7,75 & La Unión Catalana (Barcelona) & 3,66 & Unión Ganadera (Sevilla) & 7,84 \\
\hline \multirow[t]{3}{*}{5} & La Agrícola Española (Barcelona) & 1) 2,35 & Banco Agrícola Andaluz (Jaén) & 2,54 & $\begin{array}{l}\text { Banco Español de Seguros } \\
\text { (Andújar/Madrid) }\end{array}$ & 2,32 \\
\hline & & 94,8 & & 89,8 & & 94,7 \\
\hline & 1925 & & 1930 & & 1935 & \\
\hline 1 & El Fénix Agrícola (Madrid) & 66,20 & El Fénix Agrícola (Madrid) & 78,50 & La Mundial (Madrid) & 82,10 \\
\hline 2 & La Mundial Agraria (Sevilla) & 10,90 & Unión Ganadera (Sevilla) & 10,60 & Unión Ganadera (Sevilla) & 15,00 \\
\hline 3 & Unión Ganadera (Sevilla) & 9,15 & La Previsora Hispalense (Sevilla) & 1) 4,49 & Europe Company (Barcelona) & 1,16 \\
\hline 4 & La Agrícola Española (Barcelona) & 1) 4,80 & Barcelona (Barcelona) & 4,24 & $\begin{array}{l}\text { Compagnie d'Assurances } \\
\text { (Francia/Madrid) }\end{array}$ & 0,80 \\
\hline \multirow[t]{2}{*}{5} & La Previsora Hispalense (Sevilla) & 3,73 & La Agrícola Española (Barcelona) & ) 0,99 & La Previsora Hispalense (Sevilla) & 0,69 \\
\hline & & 94,8 & & 98,8 & & 99,8 \\
\hline
\end{tabular}

Fuentes: Boletín Oficial de Seguros (1913-1926); Boletín Oficial de la Inspección Mercantil y de Seguros (19271928); Revista de Previsión (1929-1934); Boletín Oficial de Seguros y Ahorro (1934-1941); Anuario Estadístico de España (1919).

37. Gaceta de Madrid, n. ${ }^{\circ}$ 75, 16/03/1933, p. 2031. 
Del otro ramo agrario, el seguro contra el pedrisco, no contamos con estadísticas oficiales hasta 1931. Parece que la actividad aseguradora aumentó a partir de 1919 con la creación de la Mutualidad Nacional del Seguro Agropecuario, fundada mediante real decreto de 9 de septiembre de 1919. La publicación de una estadística específica a partir de 1931 se puede relacionar con un decreto-ley del Ministerio de Trabajo, publicado en 1929 que transformó la Mutualidad Nacional del Seguro Agropecuario en la Comisaría de Seguros del Campo. A partir de su aprobación, las operaciones de seguro se cedieron a las compañías y con ello se estimuló la vuelta de la actividad privada al ramo contra el pedrisco. De nuevo, al igual que en el ramo de ganado, existió una creciente concentración de las primas en unas pocas compañías: una española, Covadonga, y las francesas L'Abeille y Compagnies d'Assurances Générales ${ }^{38}$. La primera fue incrementando su cuota de mercado respecto de las francesas hasta alcanzar el 50\% en 1933. Sólo a partir de 1934 se incorporó la mutua patronal de accidentes de trabajo Mutua de Seguros Agrícolas (Mapfre), fundada por la Asociación de Propietarios de Fincas Rústicas de España (Tabla 4). Esta entrada perjudicó a las tres anteriores, ya que Mapfre fue asumiendo el 15\% y el 21\% del mercado en 1934 y 1935, respectivamente.

TABLA 4

Primas recaudadas en el ramo de pedrisco, 1931-1935 (en pesetas corrientes)

\begin{tabular}{lrrrrrr}
\hline Razón social & País & $\mathbf{1 9 3 1}$ & $\mathbf{1 9 3 2}$ & $\mathbf{1 9 3 3}$ & $\mathbf{1 9 3 4}$ & $\mathbf{1 9 3 5}$ \\
\hline Covadonga & España & 603.122 & 881.134 & 692.555 & 922.783 & 762.212 \\
L'Abeille & Francia & 439.930 & 558.959 & 401.000 & 570.646 & 491.232 \\
Compagnies d'Assurances Générales & Francia & 312.291 & 427.623 & 296.217 & 447.127 & 324.711 \\
Mutua de Seguros Agrícolas (MAPFRE) & España & - & - & - & 346.646 & 423.805 \\
\hline TOTAL & & $\mathbf{1 . 3 5 5 . 3 4 3}$ & $\mathbf{1 . 8 6 7 . 7 1 6}$ & $\mathbf{1 . 3 8 9 . 7 7 2}$ & $\mathbf{2 . 2 8 7 . 2 0 2}$ & $\mathbf{2 . 0 0 1 . 9 6 0}$ \\
\hline
\end{tabular}

Nota: hasta 1930 las primas del ramo de pedrisco aparecen incluidas en las estadísticas, sin identificar, en un grupo denominado otros ramos.

Fuente: Revista de Previsión (1929-1934); Boletín Oficial de Seguros y Ahorro (1934-1941); Anuario Estadistico de España (1919).

Este escaso interés del mercado privado por los seguros agrarios en la segunda década del siglo Xx coexistió con la larga tradición decimonónica de mutualidades que persistía en toda España, principalmente en la zona del norte y levante, en el ámbito local o provincial. En su mayor parte el mutualismo estuvo impulsado por instituciones y asocia-

38. La compañía Covadonga se había fundado en Madrid en 1924. En el anuario español de seguros del ejercicio de 1932, tiene constituido un capital social de cinco millones de pesetas, aunque sólo desembolsado 1,25 millones. En esos momentos practicaba el ramo de incendios, marítimo y pedrisco. 
ciones patronales y sindicatos. Entre las primeras destacan las diputaciones vascas y navarra (Lanza, 1996: 194) ${ }^{39}$. En el caso de Guipúzcoa, pervivían viejas hermandades de seguro mutuo de ganado denominadas anaitasunas, que continuaban operando a pesar de que su función de socorro tropezaba con la dificultad de valorar el riesgo y hacer frente a las indemnizaciones de los socios, en especial, en etapas de pestes ${ }^{40}$. En 1907 la Diputación de Guipúzcoa, en su intento de modernizar el sector agrario, fundó la Casa Provincial de Reaseguros, donde integró a la mayoría de las sociedades y asociaciones de Guipúzcoa que se dedicaban al seguro de ganado (Lanza, 1996: 193).

Al margen de estas iniciativas públicas regionales, el Estado central había participado escasamente en el respaldo del seguro agrario. En la segunda década del siglo Xx, las incipientes presiones patronales dieron como resultado las primeras intervenciones. Entre ellas cabe citar el ya nombrado proyecto de ley de seguros agrícolas de 1902, que constituye el primer intento de la Administración para fomentar un sistema de seguros agrarios, dejando a las diputaciones la iniciativa de establecer estos seguros en cada provincia (Melgarejo \& López, 2016). Un nuevo paso en este sentido fue la conferencia de seguros agrícolas convocada por real decreto de 30 de agosto de 1917 por el ministro de Fomento, el vizconde de Eza. De ella saldría la propuesta para poner en marcha un seguro basado en un sistema mutualista, donde se dio participación a los distintos ámbitos, local, provincial, regional y nacional, a través de cajas de compensación (Bardají, Escribano \& Garrido, 2016).

A esta iniciativa le siguió la real orden del ministro de Fomento Francesc Cambó, que nombró un comité para el estudio y propuesta para la organización de los seguros agrícolas. Finalmente, mediante un decreto del 10 de abril de 1919 el ministro de Hacienda, el marqués de Cortina, autorizaba al Comité Oficial del Seguro Marítimo a asumir, a cargo del Estado, en coaseguro, los riesgos de incendio de cosechas y el de pedrisco que les cedieran las mutualidades legalmente constituidas. Los representantes de la Asociación General de Agricultores de España interpretaron estas medidas como de escasa repercu$\operatorname{sión}^{41}$. Lo más valorado fue que esta institución permitía asegurar los incendios de cosechas o contra la propiedad agrícola derivados de actos sociales violentos (caso de los

39. Cabrera (2002: 37) identifica Santander, País Vasco, Navarra, los Pirineos aragoneses y parte de Cataluña como las zonas de predominio de los pequeños propietarios y arrendatarios medios.

40. En 1918 existían 34 anaitasunas en la provincia de Guipúzcoa, con un número de socios de 1.317. En ese año cubrían un total de 6.194 reses por un capital de 3.201.260 pesetas. Revista Los Seguros, 15/08/1919, pp. 117-120.

41. La Asociación General de Agricultores se creó en 1880-1881. El origen estuvo muy vinculado a la Asociación de Ingenieros Agrónomos, si bien se admitía como socios a una heterogeneidad de profesiones agrarias, lo que, entre otras razones, pudo contribuir a que no arraigara como la gran asociación de los propietarios y las clases medias rurales (PAN-MonTojo, 2005: 110). 
motines, excluidos por las compañías de seguros) ${ }^{42}$. Esta asociación reclamaba la necesidad de un mayor número de iniciativas privadas y públicas.

La misma asociación patronal había fundado en 1917 la Caja de Seguros Mutuos contra el pedrisco, que protegía de forma privada a los mutualistas por un valor de once millones de pesetas. Los ponentes, sin embargo, aclaraban que estas iniciativas eran posibles en los llamados riesgos asegurables (pedrisco, incendio de cosechas, mortalidad, enfermedad y accidentes de ganado). Los demás riesgos agrarios no eran asegurables y por tanto el Estado, y en especial, un organismo de previsión como era el Instituto Nacional de Previsión (INP), debía crear una mutualidad para estos riesgos y así se podrían evitar los costes de compensación que inevitablemente y de forma habitual realizaba el Estado para los damnificados en riesgos catastróficos. Coincidencia en el tiempo o resultado de las presiones de este tipo de asociaciones, lo cierto es que poco después, mediante el real decreto de 9 de septiembre de 1919, se creó la Mutualidad Nacional del Seguro Agropecuario, compuesta exclusivamente con capital público, que, según Bardají, Escribano y Garrido (2016), tendría unos resultados muy limitados. Del mismo parecer son Melgarejo y López (2016: 332-334) cuando explican que en la práctica se redujo al ramo de pedrisco y con unos resultados deficitarios que obligaron al Estado a auxiliarla sólo dos años más tarde con una subvención anual de 250.000 pesetas ${ }^{43}$. A pesar de ello, llegó a tener una organización de 1.108 agencias en toda España ${ }^{44}$. La mutualidad en su origen surgió vinculada al Ministerio de Fomento, bajo la competencia de la Dirección General de Agricultura, Minas y Montes, no al Ministerio de Trabajo y al INP como reclamaba la patronal agraria.

La presión de los lobbies patronales parece estar detrás de muchas de las intervenciones posteriores del Estado en el ámbito del seguro agrario. En estas instituciones la representación patronal fue dominante. Cuando en 1929 por decreto-ley del Ministerio de Trabajo, la Mutualidad Nacional del Seguro Agropecuario se convirtió en la Comisaría de Seguros del Campo, ahora sí dependiente de la Inspección General de Previsión, además de a una mayoría de representantes técnicos, se incluyó a un miembro de la Asociación General de Agricultores, otro de la Asociación General de Ganaderos y otro de

42. Asamblea Agraria de Alcázar de San Juan de 11 de julio de 1919 de la Asociación General de Agricultores de España. Ponencia de los Señores Marqués de Casa-Pacheco, Fernández Navarro y Alcaraz Jaén. Madrid, 1919.

43. Los objetivos de la Mutualidad en el Estatuto de la Mutualidad Nacional del Seguro Agropecuario. Gaceta de Madrid, n. ${ }^{\circ} 319,15 / 11 / 1919$.

44. Gaceta de Madrid, n. ${ }^{\circ} 28,28 / 01 / 1927$. 
la Confederación Nacional Católico-Agraria ${ }^{45}$. Con esta conversión de mutualidad a comisaría, se terminó una experiencia de mutualidad con capital exclusivamente público para incorporar el papel de la actividad privada. Poco después, en la etapa de la Segunda República, la Comisaría de Seguros del Campo se transformó en el Servicio Nacional de Seguros Agrarios (1932) y en el Servicio Nacional de Seguros del Campo (1934) (Melgarejo \& López, 2016: 332-334).

Las grandes patronales agrarias ejercieron poco protagonismo directo en el seguro agrario, presionando a la clase política o dejando al mercado que asumiera esta responsabilidad. Sólo hubo una excepción con el seguro de accidentes de trabajo en el sector agrario. Al aprobarse su obligatoriedad en 1931 y 1932-1933, se crearon rápidamente en toda España hasta 178 mutualidades patronales agrarias de accidentes del trabajo (1935) (Pons, 2006). Los empresarios agrarios hicieron de la obligación un negocio y algunas de ellas se convirtieron en grandes aseguradoras (véase el origen de Mapfre) (Tortella, Caruana \& García Ruíz, 2009). Al crear estas mutuas de seguro para asegurar a sus trabajadores agrarios, los empresarios obtuvieron unas primas más bajas, el control médico de sus trabajadores accidentados y la devolución de extornos en los casos, muy habituales, de la existencia de beneficios al terminar el año. Algo pudo beneficiar al resto de los ramos del seguro agrario, puesto que algunas de estas mutualidades, aprovechando su infraestructura, extendieron su actividad al ramo de incendios (seguro de incendio de cosechas) o al ramo de pedrisco.

\section{CONCLUSIONES}

La actitud ante el riesgo que conlleva la actividad agraria ha sido una constante a lo largo de la historia. Las respuestas practicadas en una agricultura precapitalista, propia de la Edad Moderna, mantienen su vigencia hasta épocas muy recientes, como el siglo xx, con una implantación muy tardía del seguro agrario. La magnitud que podía alcanzar el riesgo lleva a que las estrategias para combatirlo o paliarlo revistan también una gran complejidad, que afecta a todos los ámbitos institucionales y a la esfera individual. Dejando a un lado las medidas de la Administración, tanto del Estado como de los concejos, destacamos la vía sociorreligiosa y la importancia que adquiere la Iglesia en este asunto. No obstante, en este trabajo, para la Edad Moderna, abordamos la gestión del riesgo en los con-

45. En abril de 1931 eran las tres entidades agropecuarias de carácter nacional. La Asociación General de Ganaderos era heredera del Honrado Concejo de la Mesta creado por real decreto en 1836. En 1914 fue declarado sindicato agrícola. La Confederación Nacional Católico-Agraria representaba al pequeño campesinado castellano y norteño. Nació en 1917 en una asamblea celebrada en Madrid (CABRERA, 1983: 63). 
tratos de arrendamiento como forma de explotación más empleada. La conclusión más definitoria sería la progresiva desaparición de la cláusula de esterilidad por la que los arrendatarios podían solicitar descuentos de la renta y la permanente adopción de la cláusula conocida como a riesgo y ventura, por la cual todos los imprevistos debían ser cubiertos enteramente por el cultivador o colono.

Durante el siglo XIX y primeras décadas del siglo Xx, dadas las dificultades normativas en la constitución de las sociedades de seguro de capital y el desinterés del negocio en el ramo agrario, las mutualidades, apoyadas institucionalmente o vinculadas a emprendedores privados, representaron casi la única oferta de cobertura de riesgos para los agricultores en diferentes regiones españolas. Las mutualidades gozaban de ventajas y debían enfrentarse a grandes inconvenientes. No disponían de capital social y, por tanto, no tenían la presión de los inexistentes accionistas para obtener beneficios a corto plazo, y mantenían una escasa organización burocrática y, por tanto, bajos gastos de gestión. Sin embargo, este mismo aspecto repercutía negativamente a la hora de controlar la tasación de los riesgos y la gestión de los siniestros y, sobre todo, en las dificultades por alcanzar una escala nacional y regional. A pesar de ello, constituyeron la fórmula óptima para asegurar en este contexto y se convirtieron en el largo plazo en la forma tradicional de cobertura en el mundo agrario, incluso ante la incorporación del seguro mercantil en etapas posteriores. El ámbito del seguro local o provincial compensaba con el conocimiento de los usufructuarios y de los bienes la incertidumbre y la falta de estadísticas. Por ello, se prefería ese tipo de sociedad frente a las grandes en las que podría haber existido una economía de escala y un mayor reparto del riesgo, pero que sufrían más el desconocimiento de los factores que incidían en la siniestralidad y una administración profesional alejada del mundo rural apegado a las formas tradicionales. En este sentido, resulta significativa la mayor implantación de las mutuas agrarias en el norte de España, en zonas de fuerte presencia de los comunales y de desarrollo ganadero.

La organización de un mercado de seguro privado en las primeras décadas del siglo $\mathrm{XX}$ no amplió la oferta sobre la cobertura del riesgo agrario. Las grandes aseguradoras extranjeras o nacionales se concentraron en otros ramos y dejaron en manos de compañías especializadas de escaso capital la débil demanda de los agricultores. Se trataba de riesgos difíciles de tasar por falta de estadísticas y con grandes dificultades técnicas. Por otra parte, las mutuas locales y provinciales buscaron el apoyo institucional y financiero de las corporaciones locales y las diputaciones provinciales, lo que consiguieron con mayor frecuencia en el norte de España. A su vez, las grandes asociaciones patronales agrarias, con mayores intereses en el resto de España, buscaron el apoyo del Estado para que creara instituciones que garantizaran la cobertura. La presión de estos lobbies consiguió finalmente que el riesgo agrario fuera progresivamente asumiéndose como una competencia 
del Estado. No obstante, el intervencionismo estatal se había iniciado en el siglo XIX, ante los grandes desembolsos que se destinaban a zonas afectadas por catástrofes. Este impulso no fue solamente legislativo, sino también de personal técnico y medios materiales.

Desde el inicio de nuestro trabajo optamos por un objeto de estudio más inclinado a la actividad privada. Eso no significa obviar el papel institucional. Así, las iniciativas del Estado resultan claramente insuficientes para afrontar los riesgos que acompañan a la actividad agraria. A medio camino podría considerarse el papel del mutualismo, con un fuerte componente de la sociedad civil, pero con frecuencia amparado por instituciones locales o provinciales.

Uno de los debates historiográficos, que consideramos amplia y lúcidamente tratado, es el del «atraso» de la agricultura española y su papel en el desarrollo económico gene$\mathrm{ral}^{46}$. No obstante, sigue resultando interesante insertar los estudios agrarios en esta perspectiva. En este sentido, cabe preguntarse: ¿qué papel jugó el seguro agrario en la modernización y crecimiento de la agricultura y ganadería? La respuesta viene marcada por la baja incidencia del mercado asegurador. Frente al despegue de otros ramos, el seguro agrario se mantiene en porcentajes de negocio muy bajos. De todas formas, esta realidad pudo deberse más a factores propios, consustanciales con las compañías aseguradoras y su potencial clientela, que con la persistencia de unas estructuras agrarias tradicionales.

\section{AGRADECIMIENTOS}

Agradecemos las consideraciones de los revisores de Historia Agraria que han contribuido con sus comentarios y críticas a la mejora sustancial de este artículo.

\section{REFERENCIAS}

AlberolA. A. (2009). La natura desfermada: Al voltant de manuscrits, impresos i imatges sobre desastres naturals en l'Espanya del segle XviII. En A. AlbERola \& J. OlcinA (Eds.), Desastre natural, vida cotidiana y religiosidad popular en la España moderna y contemporánea (pp. 17-76). Alicante: Universidad de Alicante.

46. Tomando como punto de inflexión la publicación de El pozo de todos los males (Pujol et al., 2001) el debate se enriqueció con las aportaciones en la revista de Historia Agraria de LlopIS (2002), Palafox (2002), Pascual y Sudrià (2002), Simpson (2002) y Pinilla (2004). 
AzCÁRATE, I. (1996). Plagas agrícolas y forestales en España en los siglos XVIII y XIX. Madrid: Ministerio de Agricultura, Pesca y Alimentación.

Bardají, I., Escribano, S. \& Garrido, A. (2016). Principios básicos de seguros agrarios. Almería: Cajamar. https://www.publicacionescajamar.es/series-tematicas/manualescajamar/principios-basicos-de-seguros-agrarios

BARRIENDOS, M. (2000). La climatología histórica en España: Primeros resultados y perspectivas de la investigación. En J. C. GARCía Codrón (Coord.), La reconstrucción del clima en época preindustrial:V Reunión Nacional de Climatología (pp. 15-56). Santander: Universidad de Cantabria.

BORSCHEID, P. \& HAUETER, N.V. (2012). World Insurance:The Evolution of a Global Risk Network. Oxford: Oxford University Press.

Blasco, Y. \& Rabetino, R. (2012). Argentina: The Changing Fortunes of the Argentinian Insurance Market. En P. BorSCHEID \& N. V. HAUETER (Eds.), World Insurance: The Evolution of a Global Risk Network (pp. 167-188). Oxford: Oxford University Press.

BuJ, A. (1996). El Estado y el control de plagas agrícolas: La lucha contra la langosta en la en la España contemporánea. Madrid: Ministerio de Agricultura, Pesca y Alimentación.

Burgaz, F. \& Pérez-Morales, M. (1996). 1902-1992: 90 años de seguros agrarios en España. Madrid: Ministerio de Agricultura, Pesca y Alimentación.

CABRERA, M. (1983). La patronal ante la II República: Organizaciones y estrategia: 1931-1936. Madrid: Siglo XXI.

CABrera, M. (2002). El poder de los empresarios: Política e intereses económicos en la España contemporánea, 1875-2000. Madrid: Taurus.

CARASA, P. (2001). Proyectos y fracasos del crédito agrícola institucional en la España contemporánea. Áreas, (21), 95-121.

CARMONA, J. (1997). Contratos agrarios, costes de transacción y riesgo en el cultivo de secano en Castilla, 1830-1936. Agricultura y Sociedad, (82), 115-150.

CARMONA, J. \& Simpson, J. (2003). El laberinto de la agricultura española: Instituciones, contratos y organización entre 1850 y 1936. Zaragoza: Prensas Universitarias de Zaragoza.

CARPIO, J. (2011). Los contratos de medianería en la explotación de las tierras de Carmona ( $2^{\mathrm{a}}$ mitad del siglo XVI). En M. GonZÁlez JiMÉNEZ (Dir.), Carmona, 7000 años de historia rural. Sevilla: Universidad de Sevilla/Ayuntamiento de Carmona.

CARPIO, J. (2012). Negocio agrario en el siglo XVI: Los arrendamientos de bueyes en Andalucía Occidental. En M. J. Pérez Álvarez \& A. Martín (Coords.), Campo y campesinos en la España Moderna (pp. 301-312). León: Universidad de León.

CARPIO, J. (2016). La gestión pública del riesgo en la economía agraria de los siglos XVI y xvir. En A. DiVittorio, N. Ostuni \& C. Barciela (Coords.), Le assicurazioni: Si- 
curezza e gestione dei rischi in Italia e Spagna tra Età Moderna e Contemporanea (pp. 111-135). Milano: Giuffré.

Catalá, J. \& Guillem, X. (2006). Control de plagas y desarrollo institucional en la estación de patología vegetal de Burjasot (Valencia) (1924-1931). Asclepio, LVIII (1), 249280.

Christian, W. A. (1991). Religiosidad local en la España de Felipe II. Madrid: Nerea.

DinsDALE, W. A. (1954). History of Accident Insurance in Great Britain. London: Stone \& Cox.

FraX, E. \& MATilla, M. J. (1998). La evolución del sector seguros en Francia y España, 1800-1936. En C. E. NúÑEZ (Ed.), Insurance in Industrial Societies: Economic Role, Agents and Market from 18th Century to Today (pp. 31-44). Sevilla: Universidad de Sevilla.

GuilleM, J. M. (2010). La difícil mayoría de edad de las sociedades de seguros por acciones en la primera mitad del siglo xIx. En J. Pons \& M. A. Pons (2010), Investigaciones históricas sobre el Seguro español (pp. 49-80). Madrid: Fundación Mapfre.

HunEK, T. (1986). Agriculturas y sociedades rurales en un sistema de producción de alimentos sujeto a incertidumbres. Agricultura y Sociedad, (38-39), 185-201.

LANA, J. M. (2001). Progresos y regresos de la vitivinicultura navarra: La acción pública y sus contextos sociales (1850-1936). En J. Carmona, J. Colomé, J. Pan-Montojo \& J. SiMPSON (Coords.), Viñas, bodegas y mercados: El cambio técnico en la vitivinicultura española, 1850-1936. Zaragoza: Prensas Universitarias de Zaragoza.

LANZA, R. (1996). La ganadería vacuna del País Vasco (1850-1950): Principales caracteres y factores de su evolución. En R. DOMínguez MARTín (Coord.), La vocación ganadera del norte de España: Del modelo tradicional a los desafíos del mercado mundial (pp. 147-206). Madrid: Ministerio de Agricultura, Alimentación y Medio Ambiente.

LLOPIS, E. (2002). Otras caras «menos amables» de la agricultura española contemporánea. Historia Agraria, (28), 179-198.

López Cordero, J. A. \& Aponte, A. (1993). Un terror sobre Faén: Las plagas de langosta (siglos XVI-XX). Jaén: Ayuntamiento de Jaén.

MARCos, A. (2000). España en los siglos XVI y XVII: Economía y sociedad. Barcelona: Crítica/Cajaduero.

MARTíN-Albo, M. (2016). Las organizaciones de agricultores y propietarios agrícolas en la España del siglo XIX: Economía, política y sociedad. Madrid: Ministerio de Agricultura, Pesca, Alimentación y Medio Ambiente.

MARTínez Soto, A. P. (2003). El cooperativismo de crédito en España, 1890-1934: Modelos, sistemas de gestión y balance de su actuación. Historia Agraria, (30), 119-150.

Matilla, M. J. (2010). La formación de capital en la España del siglo XIX: Las compañías de seguros. En J. Pons \& M. A. Pons (2010), Investigaciones históricas sobre el Seguro español (pp. 17-48). Madrid: Fundación Mapfre. 
Matthews, S. (2005). Cattle Clubs, Insurance and Plague in the Mid-Nineteenth Century. The Agricultural History Review, 53 (2), 192-211.

McCloskey, D. (1991). The Prudent Peasant: New Findings on Open Fields. The Fournal of Economic History, 51 (2), 343-355.

Melgarejo, J. \& López Ortiz, M. I. (2016). Análisis económico e institucional de los seguros agropecuarios en España. En A. Di VitTorio, N. Ostuni \& C. Barciela (Coords.), Le assicurazioni: Sicurezza e gestione dei rischi in Italia e Spagna tra Età Moderna e Contemporanea (pp. 169-192). Milano: Giuffré.

MorAl, J. DEL (1979). La agricultura española a mediados del s. XIX, 1850-1870. Madrid: Ministerio de Agricultura.

PALAFOX, J. (2002). Las agriculturas españolas en los siglos XIX y XX: ¿El mejor de los mundos posibles? Historia Agraria, (28), 199-205.

Pan-Montojo, J. (1994). La bodega del mundo: La vid y el vino en España (1800-1936). Madrid: Alianza.

Pan-Montojo, J. (2005). Apostolado, profesión y tecnología: Una historia de los ingenieros agrónomos en España. Madrid: Ministerio de Agricultura, Pesca y Alimentación/Asociación Nacional de Ingenieros Agrónomos.

Pascual, P. \& SudriÁ, C. (2002). Notas sobre El pozo... Historia Agraria, (28), 207-216.

Pearson, R. (1997). Towards an Historical Model of Services Innovation: The Case of the Insurance Industry, 1700-1914. The Economic History Review, 50 (2), 235-256.

PeArson, R. (2002). Moral Hazard and the Assessment of Insurance Risk in Eighteenthand Early-Nineteenth Century Britain. Business History Review, 76 (1), 1-35.

Pérez Samper, M. A. (2009). Alimentación y desastres naturales. En A. Alberola \& J. OlCINA (Eds.), Desastre natural, vida cotidiana y religiosidad popular en la España moderna y contemporánea (pp. 131-208). Alicante: Universidad de Alicante.

PERIS, T. (2009). La religiosidad instrumental comunitaria en la Ribera del Júcar durante los siglos XVI-XVIII: El ejemplo de las rogativas. En A. Alberola \& J. Olcina (Eds.), Desastre natural, vida cotidiana y religiosidad popular en la España moderna y contemporánea (pp. 335-389). Alicante: Universidad de Alicante.

PILUso, G. (2012). Italy: Building on a Long Insurance Heritage. En P. BorscheID \& N. V. HAUETER, World Insurance:The Evolution of a Global Risk Network (pp. 167-188). Oxford: Oxford University Press.

PINILLA, V. (2004). Sobre la agricultura y el crecimiento económico en España, 18001935. Historia Agraria, (34), 137-162.

Pons, J. (2006). El seguro de accidentes de trabajo en España: De la obligación al negocio (1900-1940). Investigaciones de Historia Económica, 2 (4), 77-100.

Pons, J. (2008). Multinational Enterprises and Institutional Regulation in the Life-Insurance Market in Spain, 1880-1935. Business History Review, (82), 87-114. 
Pons, J. (2016). La transformación del seguro español en el siglo XIX. En A. Di ViTToRIO, N. Ostuni \& C. BARCIELA (Coords.), Le assicurazioni: Sicurezza e gestione dei rischi in Italia e Spagna tra Età Moderna e Contemporanea (pp. 327-358). Milano: Giuffré.

Pujol, J. et al. (2001). El pozo de todos los males: Sobre el atraso en la agricultura espanola contemporánea. Barcelona: Crítica.

SANZ LARROCA, J. C. (2012). Las respuestas religiosas ante las plagas del campo en el XVII español: El hombre frente a la naturaleza. Saarbrücken: Editorial Académica Española.

Simpson, J. P. (2002). «El pozo», y el debate sobre la agricultura española. Historia Agraria, (28), 217-228.

Sobrado, H. (2003). Los enemigos del campesino: La lucha contra el lobo y otras «alimañas» nocivas para la agricultura en la Galicia de la Edad Moderna. Obradoiro de Historia Moderna, (12), 105-139.

STEAD, D. R. (2004). Risk and Risk Management in English Agriculture, c. 1750-1850. The Economic History Review, 57 (2), 334-361.

Tortella, G., Caruana, L., García Ruiz, J. L., Manzano, A. \& Pons, J. (2014). Historia del seguro en España. Madrid: Fundación Mapfre.

Tortella, G., Caruana, L. \& García Ruiz, J. L. (2009). Mapfre 1933/2008: De mutua a multinacional. Madrid: Fundación Mapfre.

Yun, B. (1987). Sobre la transición al capitalismo en Castilla: Economía y sociedad en Tierra de Campos (1500-1830). Salamanca: Junta de Castilla y León.

Vázquez Lesmes, R. \& Santiago, C. (1993). Las plagas de langosta en Córdoba. Córdoba: Cajasur. 